практическим занятиям на симуляционной площадке, они легко адаптировались на рабочих местах.

Таким образом, обобщение собственного педагогического опыта позволяет констатировать, что реализация контекстного подхода, создание симуляционых центров и внедрение в учебнообразовательный процесс модели бережливых технологий, содействуют созданию условий для формирования у обучающихся общих и профессиональных компетенций, приобретению ими первичного практического опыта работы в условиях бережливого производства, повышая тем самым качество подготовки будущих медицинских работников.

\section{Список литературы:}

1. Вербицкий А.А. Активное обучение в высшей школе: контекстный подход. - М.: Просвещение, 2001. - 538 с.

2. Вербицкий А.А. Деловая игра как форма контекстного обучения и квазипрофессиональной деятельности студентов // Педагогика и психология образования. 2009. № 4.

УДК 782

ГРНТИ 18.41 .51
3. Гринченко Е.Л. Анализ состояния проблемы самосовершенствования студентов медицинского вуза в свете компетентностного подхода // Актуальные проблемы современной науки, 2012. - № 1 (63). - С. 48-51.

4. Негодов В.Е. Правовое регулирование организации и управления процессами модернизации здравоохранения в Российской Федерации [Текст]: Дис. ... канд. юрид. наук / В.Е. Негодов. - Москва, 2012. - 163 с.

5. Орлова М.А. Возможности игромоделирования как метода квазипрофессиональной направленности обучения в логике компетентностного подхода / M. А. Орлова. - Текст: непосредственный // Проблемы и перспективы развития образования: материалы I Междунар. науч. конф. (г. Пермь, апрель 2011 г.). Т. 2. - Пермь: Меркурий, 2011. - С. 108-111.

6. Шевелева Н.В. Социально-педагогические условия организации практико-ориентированного обучения в системе среднего профессионального образования // Вестник БелИРО, 2019. - т. 6, № 4 (14). - C. $62-69$

ПРАКТИЧЕСКАЯ РАБОТА ПО ПОСТАНОВКЕ ГОЛОСА, ЧАСТЬ V. РАБОТА НАД ПРОИЗВЕДЕНИЕМ

DOI: $10.31618 /$ ESU.2413-9335.2021.1.87.1400

Покровский Андрей Викторович член-корреспондент Петровской Академии наук и искусств. Россия, г.Санкт-Петербург

\title{
PRACTICAL WORK ON VOICE TRAINING, PART V. WORK ON A WORK OF ART
}

Pokrovskiy A. . corresponding member of the Peter Academy of Sciences and arts.

Russia, St. Petersburg

\begin{abstract}
The article examines the General provisions of vocal pedagogy: the relevance of the issue, principles, goals, objectives and methods of teaching singing; the criteria, methods of selection and basic skills necessary for those wishing to learn vocal art.

\section{АННОТАЦИЯ}

В статье исследуются общие положения вокальной педагогики: актуальность вопроса, принципы, цели, задачи и методы обучения пению; рассматриваются критерии, способы отбора и основные навыки, необходимые для желающих обучаться вокальному искусству.

Key words: vocal, singing, academic singing, vocal pedagogy, voice production, methods of teaching singing.

Ключевые слова: вокал, пение, академическое пение, вокальная педагогика, постановка голоса, методы обучения пению.

\section{Работа над текстом}

Чтобы работа над текстом была результативной, предварительно учащемуся необходимо дополнительно уделить внимание работе над дикцией и артикуляцией. Полезно несколько раз прочитать весь текст перед зеркалом, следя за ясностью произношения и четкостью артикуляции. Проговаривая текст, важно брать

дыхание в тех же местах, где это предусмотрено в музыкальном произведении, поскольку от этого будет зависеть звучность голоса и выразительность при пении.

Приступая к пропеванию произведения, нужно уметь перенести в исполнение отработанные без музыки элементы речевой интонации и выразительные акценты. Чтобы это получилось
\end{abstract}


легко, необходимо заранее, на этапе работы над текстом без музыки, найти речевые кульминации и тембровую окраску слов.

\section{Работа над художественным образом}

Воплощение художественного образа вокальных произведений происходит через поэтический текст, мимику и жесты исполнителя, а также через его сценическое обаяние. Освоить данный комплекс выразительных средств необходимо в той или иной степени каждому вокалисту, поскольку без этого будет невозможным выйти на профессиональный уровень и стать настоящим мастером сцены.

Обучающийся должен уметь легко представлять любое действие или образ и быстро приводить себя в рабочее состояние для их воплощения. В вокальной практике довольно редко встречаются исполнители, от природы одаренные совершенными актерскими талантами, поэтому приобретению сценических навыков и умений необходимо уделять дополнительное внимание.

Развитие актерских способностей должно проходить параллельно с работой над вокальными навыками и под контролем опытного наставника. Базовые навыки поведения певца на сцене, такие, как правильная постановка корпуса и естественная манера исполнения, обычно усваиваются с первых же уроков по постановке голоса. Более сложные умения вырабатываются постепенно. Вначале это будет довольно непросто, но педагог, сам обладающий артистизмом и сценическим опытом, без труда направит начинающего вокалиста в верном направлении, раскрывая законы поведения на сцене во время пения.

Осмыслению и освоению сценических навыков, а также их расширению в значительной степени способствует частое посещение театральных представлений и наблюдение за игрой опытных актеров.

\section{Сценические навыки}

Первые выступления начинающих вокалистов перед публикой редко бывают удачными. Впервые оказавшись на сцене и осознавая всю ответственность, исполнитель, как правило, находится в сильном волнении, результатом которого являются внутренние и внешние зажимы и потеря контроля над собой, что приводит к невозможности продемонстрировать вокальные навыки, отработанные за предыдущий период в спокойной обстановке учебного класса.

Сценическое обаяние начинающего певца также страдает из-за такого напряжения. Зритель, как под увеличительным стеклом, видит всю внутреннюю работу вокалиста и его физические недостатки, на которые в обычной жизни никто не обращает внимание. Осознавая это, исполнитель начинает стараться, заранее готовиться к сложным техническим моментам, что, в свою очередь, его дополнительно зажимает и сковывает.

Для того, чтобы развить внутреннюю и внешнюю свободу, а также самоконтроль при публичных выступлениях, необходимо развивать соответствующие навыки. Первоначально вокалист должен научиться справляться со своим сценическим волнением. Выработать это помогут частые выходы на сцену. Кроме того, во время регулярных занятий в классе нужно внимательно следить за тем, чтобы осанка, постановка корпуса, артистизм и актерская подача исполнителя были такими же, как при публичном выступлении.

Хорошо так же освоить основные правила поведения певца на сцене:

1.Занять удобную и естественную позу. Хорошо и удобно стоять на обеих ногах, что обеспечивает равномерное распределение нагрузки на все тело.

2.Выпрямить спину и расправить плечи, что обеспечивает полноценное дыхание.

3.Свободно держать голову, не задирая и не опуская ее чрезмерно. Такое положение создает наиболее оптимальные условия для работы гортани.

4.Лицо должно быть естественным и одухотворенным, этому способствует состояние легкой полуулыбки, что производит приятное впечатление на зрителей.

5.Руки должны быть свободны, мягки и естественны. Это позволит в нужный момент сделать верный сценический жест.

6.Не торопиться начать петь, не успокоив дыхание.

7.Определить свое рабочее пространство и сосредоточить внимание, вспомнив о том, ради чего ты это делаешь.

8.Приготовившись, показать легким кивком головы концертмейстеру свою готовность начать слушать музыкальное вступление и постараться все сделать так, как уже много раз получалось в учебном классе.

После каждого сценического выступления полезно вместе с учеником проанализировать все моменты прошедшего исполнения и дать советы, чтобы следующее выступление прошло еще успешней. Такой подход поможет молодому исполнителю постепенно научиться контролировать себя, выходя на сцену, что позволит ему при исполнении не отвлекаться на посторонние задачи, а думать только о музыке.

\section{Воспитание музыканта-исполнителя}

При воспитании вокалиста особенно важно, чтобы работа над техническим совершенствованием голосового аппарата шла рука об руку с раскрытием образной сферы и музыкальным развитием певца. При перегибе в ту или другую сторону неизменно будет страдать результат, так как техническое совершенствование служит лишь средством художественного воплощения творческого замысла композитора.

Воспитанию всесторонне развитой творческой личности будет способствовать накопление художественного опыта, возникающего от взаимодействия с искусством во всех его проявлениях - музыкой, поэзией, живописью, литературой и архитектурой. То есть пребывание личности в творческой среде будет активно 
способствовать полноценному развитию индивидуальности исполнителя.

Способность начинающего исполнителя пользоваться всеми возможностями своего голоса, музыкальность и выразительность развиваются при помощи умения включать воображение и чувствовать музыку. Перед тем, как взять в работу новое произведение, необходимо его несколько раз прослушать и предложить воспитаннику немного пофантазировать, ответив на следующие вопросы:

- Что он думает о произведении?

- Где, и при каких обстоятельствах развивается действие сюжета?

- Какой характер и выражение лица у героя, как он выглядит и во что одет?

- Для кого предназначается данный поэтический текст?

Такая подробная работа разовьет воображение начинающего вокалиста и подготовит его к последующему сценическому выступлению.

\section{Заключение}

Каждому начинающему певцу нужно иметь терпение учиться преодолевать трудности и добиваться результатов. Пение - это не интуитивное действие, а сознательный процесс, который требует постоянной и кропотливой работы. Если начинающий вокалист не проводит такую работу, он не сможет добиться успеха.

Певческие навыки приобретаются на протяжении длительного времени, требуя постоянного развития, тренировки и корректировки. Обучаясь пению, человек совершенствуется не только физически, но и духовно: расширяется его творческий потенциал и общекультурный уровень, что безусловно важно в жизни любого человека. Пение воздействует на человека при помощи художественных образов, что расширяет жизненный опыт и обогащает эмоциональную сферу, положительно влияя на нравственное воспитание.

\section{Список использованной литературы:} 2000

1.Багадуров В. Вокальное воспитание. - СПб.

2.Варламов А. Школа пения. - СПб. 2008

3.Выготский Л. Психология искусства. - М. 2018

4.Гарсиа М. Полная школа пения. - М. 1957

5.Далецкий О. Школа пения. - М. 2007

6.Дейша-Сионицкая М. Пение в ощущениях. СПб. 2014

7.Дмитриев Л. В классе профессора М.Э. Донец-Тессейр. - М. 1974

8.Дмитриев Л. Основы вокальной методики. М. 2000

9.Емельянов В. Развитие голоса. - СПб. 2003

10.Кабалевский Д. Воспитание ума и сердца. M. 1981

11.Лемешев С. Путь к искусству. - М. 1982

12.Матонис В. Музыкально-эстетическое воспитание личности. - Л. 1988

13.Морозов В. Искусство резонансного пения. - M. 2002

14.Назаренко И. Искусство пения. - М.-Л. 1948

15.Павлищева О. Методика постановки голоса. - Л. 1964

16.Панофка Г. Искусство пения. - М. 1968

17.Фучито С., Бейер Б. Вокальная методика Энрико Карузо. - СПб. 2004

18.Юшманов В. Вокальная техника и ее парадоксы. - СПб. 2001

376.1 УДК

14.35 ГРНТИ

\section{ОБ ИНДИВИДУАЛЬНОЙ ОБРАЗОВАТЕЛЬНОЙ ТРАЕКТОРИИ СТУДЕНТОВ В ВУЗЕ} DOI: 10.31618/ESU.2413-9335.2021.1.87.1401

Рахымбеков Айтбай Жапарович

к.ф-м.н, доцент кафедры Агрономии и технических дисичиплин, НАО Жетысуский университет имени Ильяса Жансугурова, г.Талдыкорган

376.1 UDC

14.35 GRNTI

\section{ABOUT THE INDIVIDUAL EDUCATIONAL TRAJECTORY OF STUDENTS AT THE UNIVERSITY}

Rakhymbekov Aitbay Zhaparovich Ph. D., Associate Professor of the Department of Agronomy and Technical Disciplines, Ilyas Zhansugurov Zhetysu University, Taldykorgan

\section{АННОТАЦИЯ}

В статье рассмотрены возможности построения оптимальной индивидуальной образовательной траектории студентов ВУЗа в направлений функционирования предметных и межпредметных знаний при решении типовых и проектных задач деятельности специалиста, а также развития конструктивного, алгоритмического мышления, когда обучаемый погружается в среду, требующую четкого планирования любых видов деятельности. 